Africa would undoubtedly be much different if Louis Leakey had failed to survive his difficult and premature birth 92 years ago and the Leakey family had never existed. Morell should be congratulated for bringing this all so clearly and competently to our attention.

Leslie C. Aiello is in the Department of Anthropology, University College London, Gower Street, London WC1E 6BT, UK.

\section{How we got here}

\section{Chris Stringer}

The Fossil Trail: How We Know What We Think We Know about Human Evolution. By Ian Tattersall. Oxford University Press: 1995. Pp. 276. £17.99, \$25.

WRITING popular books on human evolution is a difficult business these days. For one thing, there is a lot of competition in the market that is regularly replenished. For another, events can move fast (see previous page). But the major stumblingblock is the problem of finding a new approach or, at least, a new angle to the story. A common approach is the historical one, showing how the subject has gradually developed through ideas and discoveries. Another is to concentrate on present debates at the expense of historical development. Ian Tattersall has tried to combine both approaches to show how received wisdom can shape interpretation and how what we expect to find influences our understanding of what we do find in the fossil record.

Tattersall has to go over some familiar ground with early influences such as Boucher de Perthes, Lamarck, Cuvier and Darwin, but he manages to find some fresh gloss to apply to his accounts of the Neanderthal, 'Pithecanthropus' and Australopithecus discoveries. Only occasionally does he fail to update some of the data he introduces here - for example, the Aurignacian is now dated well beyond 32,000 years at several European sites, and the Alpine glacial-interglacial stage names have generally been abandoned away from their type areas.

Tattersall's views come through strongly, and can be nicely encapsulated in this extract from his discussion of multiregional evolution:

This viewpoint does seem to me to illustrate, better than any other current example, the extreme parochiality with which paleoanthropology is cursed. Up to this point, it appears, we paleoanthropologists have proven unable as a group to shed our major historical burden: the birth of our science out of the study of human anatomy, rather than out of the comparative anatomy and geology from which other areas of vertebrate paleontology emerged. Under the dead hand of this heritage, which places our species at the center of the academic universe, we seem incapable of seeing Homo sapiens as simply one more species among many. We constantly seek special explanations for ourselves. And, perhaps worst of all, we are afflicted with a tradition of looking for variability in the collections of fossils, rather than for diversity.

Couple this with an historical bias towards gradual evolutionary change, and it quickly becomes clear why Tattersall is so disenchanted with many aspects of mainstream palaeoanthropological thinking.

The debate on species recognition in fossil hominids is one in which Tattersall is actively engaged, and one of his consistent themes in the book is how, ever since the naming of Homo neanderthalensis by William King in 1864, hominid species have been named and then lost at a fairly steady rate, thus keeping the number of recognized species at a low level. His feeling, which I share, is that the three generally accepted species of the genus Homo - habilis, erectus and sapiens - are certainly an underestimate of the number that really existed. Each of these species can probably be split into two at least, and the conventional early hominid story is probably also an oversimplified one in terms of recognized species, if not of genera.

But Tattersall also points out, quite appropriately, that closely related species may differ little in terms of bony or dental morphology (the only aspects likely to have fossilized) and argues that we should concentrate on the variation between modern species as a yardstick for fossils rather than the variation within them. His argument is that if distinct 'morphs' can be recognized in fossil remains, then different species are indeed present. In principle this sounds fine, but the problem is that, for example, the crania of North American Inuit can be fairly consistently distinguished from those of Native Australians and yet these are both indubitably members of one species, Homo sapiens. In practical terms, I find it difficult to apply the morph rule except in the most extreme fossil cases, such as Neanderthals and Asian Homo erectus, where really distinct and surely specific patterns do exist. In the late Middle Pleistocene of Africa and Asia, for example, the morphs seem much fuzzier.

Nevertheless, Tattersall's approach is surely more realistic than the extreme lumping tendencies that have predominated over the past hundred years, and it would be nice to think that this "refreshingly opinionated" book (to quote the cover) will have a lasting influence on the next generation of palaeoanthropologists.

Chris Stringer is in the Department of Palaeontology, Natural History Museum, Cromwell Road, London SW7 5BD, UK.

\section{Children's Books}

Nature plans to publish on 16 November a supplement in which children's books and software and software will be reviewed. The supplement will cover science books and software for children of all age groups.

Publishers are invited to send suitable material for consideration, taking note of the following criteria:

Only books and software issued in 1995 will be considered;

- Books and software dealing with any aspect of science, technology, medicine, natural history or the environment are eligible (including encyclopaedias, dictionaries and games), although school curricula texts are excluded;

- The main language used must be English;

- If possible, cross-platform software (both Macintosh and $\mathrm{PC}$ ) should be provided.

Deadline for submission is 22 September.

Publications for review should be sent, together with details of price and availability, to Peter Tallack, Book Review Editor, Nature, 4 Crinan Street, London N1 9XW, UK (tel: +44 (0)171 843 4567; fax: +44 (0)171 843 4596/7; e-mail: p.tallack@nature.com).

\section{New in paperback}

\section{Newton's Clock: Chaos in the Solar}

System by Ivars Peterson. W. H. Freeman, $£ 11.95$. A readable popular history of the relationship between mathematics, astronomy and humankind's desire to understand the Solar System.

Control of Crop Diseases by W. R. Carlile (2nd edn). Cambridge University Press, $£ 12.95$. This brief introduction to modern disease control in commercial crops has been updated to include changes in practices and legislation that have come into effect since the first edition was published in 1988. Also includes a new chapter on the detection and identification of disease, with emphasis on molecular diagnostic techniques.

Gene Cloning: An Introduction by T. A. Brown (3rd edn). Chapman and Hall, $£ 17.99$. This well established introductory text, which is aimed at undergraduates and those who have little or no previous experience of cloning techniques, now contains new chapters on the polymerase chain reaction and plant molecular biology.

Enrico Fermi, Physicist by Emilo Segre. University of Chicago Press, \$13.95, £11.25. "Authoritative, revealing and inspiring," said Nature's reviewer of the book when it first appeared in 1970. "It covers in a masterly fashion the most exciting thirty years of modern physics and the character and activities of one of its greatest contributors".

How to Write and Publish a Scientific Paper by Robert A. Day (4th edn). Cambridge University Press, $£ 12.95$. Gives sensible advice on all manner of subjects, including how to write book reviews. 